\title{
A POTENTE POESIA INDÍGENA DE MÁRCIA WAYNA KAMBEBA EM O LUGAR DO SABER
}

\section{RESENHA}

KAMBEBA, Márcia Wayna. O lugar do saber. São Leopoldo: Casa Leiria, 2018.

\section{Walace Rodrigues ${ }^{1}$}

A obra em análise é um livro de sessenta e quatro páginas e editado pela Casa Leiria, de São Leopoldo/RS. O livro teve apoio do Observatório Nacional de Justiça Socioambiental Luciano Mendes de Almeida - OLMA, ligado à Província dos Jesuítas do Brasil. Tal livro coloca-se como o volume 1 da Série Saberes Tradicionais desta editora e traz poemas da escritora indígena Márcia Wayna Kambeba.

Vale falar um pouco da autora para melhor compreender esta obra poética. Márcia Kambeba é uma indígena amazonense da etnia Omágua/Kambeba. Ela nasceu na aldeia Tikuna chamada Belém do Solimões, no Alto Solimões/AM. Kambeba vive em Belém e trabalha a partir desta cidade urbana. Sendo muito requisitada atualmente, ela visitou vários cantos do Brasil e do mundo, participando de eventos, programas de rádio e televisão, executando suas performances e dando entrevistas. Sua arte vai além da poesia, pois ela canta em sua língua indígena, compõe suas próprias canções, dá oficinas sobre conhecimentos indígenas, conta histórias, é fotógrafa e pesquisadora. Enfim, ela é uma verdadeira performer, associando poesia, música, dança, línguas, vestimentas, imagens, etc. Não podemos compreender, portanto, seus poemas sem compreender o contexto de seus vários trabalhos artísticos, pois eles todos parecem compor a personalidade artística

\footnotetext{
${ }^{1}$ Pós-Doutor pela Universidade de Brasília - UnB/POSLIT. Doutor em Humanidades, mestre em Estudos Latino-Americanos e Ameríndios e mestre em História da Arte Moderna e Contemporânea pela Universiteit Leiden (Países Baixos). Pós-graduado (lato sensu) em Educação Infantil pelo Centro Universitário Barão de Mauá - SP. Licenciado Pleno em Educação Artística pela UERJ e com complementação pedagógica em Pedagogia. Professor Adjunto da Universidade Federal do Tocantins (UFT). Docente do Programa de PósGraduação em Demandas Populares e Dinâmicas Regionais (PPGDire) e da Pós-Graduação em Ensino de Língua e Literatura (PPGL). Pesquisador no grupo de pesquisa Grupo de Estudos do Sentido - Tocantins GESTO, da Universidade Federal do Tocantins - UFT.
} 
de Márcia Kambeba.

O livro O lugar do saber, de 2018, é o segundo livro individual de poemas de Márcia Kambeba. O primeiro foi Ay kakyri Tama (Eu moro na cidade), publicado pela Grafisa em 2013. Seu primeiro livro está na segunda edição. Na obra O lugar do saber, Márcia Kambeba brinda-nos com quarenta e quatro poemas que remetem a saberes, fazeres e sentimentos dos povos indígenas amazônicos. Na página onze temos um prefácio do professor Aloir Pacini, da Universidade Federal de Mato Grosso - UFMT, revelando um pouco da obra de Kambeba: "a autora é brilhante atuando no seu teatro, na música e na sonoridade de seus versos, o que não aparece na escrita, somente sugere, acena" (2018, p. 11).

As fotografias da capa e no interior do livro são de autoria da própria Márcia Kambeba, confirmando seus múltiplos talentos artísticos. Há quatro imagens fotográficas nesta obra: uma na capa, uma no começo de livro, outra no meio dele e mais uma no final do livro. Tais imagens baseiam-se na água de um rio ou igarapé como tema central. A fotógrafa buscou exprimir-se através deste elemento natural tão importante para os indígenas brasileiros e necessário à vida de todos os seres da floresta e da cidade.

Kambeba ainda nos dá uma introdução sobre a obra e as culturas indígenas em "O rio que corre em mim é um rio de memórias", da página doze à quatorze, revelando a influência dos saberes aprendidos de sua avó Assunta e seu pai Baga (padrasto de sua mãe), anciãos de seu povo. Sabemos que nas comunidades indígenas onde há idosos há a perpetuação da tradição dos costumes, dos rituais e das celebrações indígenas, pois da memória deles dependem os mais novos para continuar sendo quem são etnicamente.

Nesta obra Márcia Kambeba revela-nos suas influências étnicas, memórias das raízes mais profundas de sua alma e identidade indígena, que fundam-se nas águas dos rios amazônicos. Kambeba fala-nos sobre isso: "Esses ensinamentos ainda mantidos hoje, contribuem para constituição de identidade, da noção de pessoa, dos valores e crenças, do coletivo social, da relação com a natureza, do respeito ao outro, do entendimento de partilha, da percepção de cada indivíduo dentro da sociedade indígena e da responsabilidade que cada pessoa carrega consigo" (2018, p. 14).

Ela conta-nos sobre o ato poético de escutar o passar do rio: "Ir escutar o rio além de se caracterizar como um momento ritualístico era uma forma de intimidade e territorialidade com o mundo das águas" (2018, p. 13). Esse silenciar proposital parece 
ter inspirado os poemas de Kambeba nesta obra. Este é um silêncio de criação artística e de reflexão para sentir e guardar dentro de si. E ela nos mostra, em seus poemas, que trouxe tudo isto dentro dela.

Kambeba começa seu livro com o poema intitulado "Mãe natureza", revelando a necessidade de uma íntima relação entre homem e natureza para a conservação da Terra Mãe e para a sobrevivência de todos os seres vivos. Muitos de seus poemas têm esse aspecto de denúncia, de protesto, de revelação dos caminhos errados que a sociedade "branca" tomou. Kambeba revela-nos uma necessidade da compreensão do homem como parte da natureza, buscando conscientizar-nos sobre o mal que sofrem as florestas, os rios, as pessoas.

No poema "Chão Kambeba" ela revela-nos o espírito combativo dos Kambeba, insistindo em verbos como resistir, lutar, reviver e ser. Tal poema é um retorno à história dos Kambeba, que necessitaram fingir que não eram desta etnia para não serem exterminados. A última estrofe do poema diz: "Hoje canto e danço para ver, / Esse povo voltar a dizer, / Sem vergonha de ser o que é / Sou Kambeba e tenho fé” (2018, p. 25).

Um outro poema que nos chamou atenção nesta obra foi aquele intitulado "Identidade". Nele Kambeba deixa-nos compreender poeticamente como lida com a questão identitária de ser indígena morando na cidade grande. Ela nos revela o preconceito de ser indígena no espaço urbano da metrópole, como que aqueles que ali estivessem habitando deixassem de ser quem são. Ela nos fala sobre quando o indígena tenta buscar trabalho na cidade: "Para trabalhar aqui, / O cabelo vai ter que cortar. / Mas a minha identidade, / Essa ele não conseguiu apagar" (2018, p. 31).

Para ressaltar mais um dos instigantes poemas deste livro, deixamos aqui um pouco do poema intitulado "Lamento da Terra": "Entenda homem branco / Esse lamento é de dor. / Está doendo, estou morrendo, / Por tua falta de amor" (2018, p. 60). Vemos que Kambeba instaura um diálogo entre os homens e a Mãe Terra. O eu lírico deste poema é a própria Mãe Terra falando, deixando perceber o quanto ela foi espoliada e ainda é maltratada. Neste sentido, a forte relação de necessidade e complementariedade entre Terra (através da natureza) e homens (incluindo indígenas e brancos) deixa-se perceber contundentemente.

Encerrando o livro, Márcia Kambeba explica-nos um pouco de como pensa sobre a questão indígena, ressaltando a importância do território para as várias etnias indígenas 
brasileiras, mostrando a necessidade da preservação da natureza para a continuação da vida das pessoas, fala-nos da importância do respeito ao outro e levantando a questão da educação escolar nas aldeias. Ela diz: "é preciso saber ler e escrever e a aldeia entende que a criança deve estudar na escola do 'branco' para contribuir com o povo na luta pelo respeito e direitos institucionais e legais aos povos" (2018, p. 63).

Notamos, ainda, na obra analisada que há uma constante busca do Eu Lírico por uma certa musicalidade, já que em cada poema percebemos a íntima ligação da poeta indígena com a oralidade, elemento-chave para a transmissão dos conhecimentos indígenas que sedimentarão as memórias. Além disto, sua poesia parece pedir para ser recitada, implorando por uma performance.

Também, podemos verificar, como revela-nos Graça Graúna, que a temática indígena atual é extensa e abrange várias áreas da vida dos povos indígenas brasileiros. Graúna (2011, p. 5) informa-nos que: “As implicações em torno dessa temática permitem compreender o aspecto da autohistória e a sua relação com a oralidade e a escrita, entre outras questões identitárias que emanam da literatura contemporânea de autoria indígena no Brasil.”

Neste sentido, vemos que o livro $O$ lugar do saber não é somente um livro de poesia, mas uma produção artística e de divulgação das culturas dos vários povos indígenas brasileiros. Márcia Kambeba coloca-se claramente numa posição de ativismo indígena, buscando sensibilizar as pessoas para as causas das várias etnias indígenas no Brasil e colaborar com a divulgação dos saberes e fazeres indígenas através das artes.

\section{REFERÊNCIAS}

GRAÚNA, Graça. Literatura Indígena: desconstruindo estereótipos, repensando preconceitos. Recife - UPE, 2011, pág. 1-5. Disponível em: < http://www.dhnet.org.br/direitos/militantes/ggrauna/ggrauna_lit_indigena_desconstruin do.pdf >. Acesso em 27 jun. 2020.

KAMBEBA, Márcia Wayna. Ay kakyri Tama (Eu moro na cidade). Manaus: Grafisa, 2013.

KAMBEBA, Márcia Wayna. O lugar do saber. São Leopoldo: Casa Leiria, 2018.

PACINI, Aloir. Prefácio. IN: KAMBEBA, Márcia Wayna. O lugar do saber. São Leopoldo: Casa Leiria, 2018. 